\title{
Evaluation of genotoxicity after acute and chronic exposure to 2,4-dichlorophenoxyacetic acid herbicide (2,4-D) in rodents using machine learning algorithms
}

\author{
Fabíola de Azevedo Mello1, Beatriz Bertholace Magalhaes Silva², \\ Emmanuela Beatriz Vantini Barreiro², Isabela Benes Franco², Isabela Melo Nogueira², \\ Pedro Henrique Nahas Chagas², José Luiz Santos Parizi³ ${ }^{3}$ Danillo Roberto Pereira ${ }^{4}$, \\ Renata Calciolari Rossi ${ }^{4}$ and Gisele Alborghetti Nai ${ }^{5}$
}

\author{
${ }^{1}$ Graduate Program in Animal Science, Universidade do Oeste Paulista (UNOESTE), Presidente Prudente, SP, Brazil \\ ${ }^{2}$ Faculty of Medicine of Presidente Prudente (FAMEPP), Universidade do Oeste Paulista (UNOESTE), \\ Presidente Prudente, SP, Brazil \\ ${ }^{3}$ Department of Pathology, Universidade do Oeste Paulista (UNOESTE), Presidente Prudente, SP, Brazil \\ ${ }^{4}$ Graduate Program on Environment and Regional Development, Universidade do Oeste Paulista (UNOESTE), \\ Presidente Prudente, SP, Brazil \\ ${ }^{5}$ Department of Pathology and the Graduate Program in Animal Science, Universidade do Oeste Paulista \\ (UNOESTE), Presidente Prudente, SP, Brazil
}

(Received June 25, 2020; Accepted September 6, 2020)

\begin{abstract}
Dichlorophenoxyacetic acid (2,4-D) is one of the most widely used herbicides in the world, but its mutagenic and carcinogenic potential is still controversial. We simulated environmental exposure to 2,4-D, with the objective of evaluating the genotoxic effect of acute and chronic exposure to 2,4-D in rodents. We also evaluated the performance of machine learning algorithms in detecting differences in exposure groups through recognition performed from genotoxic characteristics. In the acute phase, 88 Swiss mice were used, distributed in five groups and exposed to nebulizations at different time intervals $(24,48,72$ and $192 \mathrm{hr})$. In the chronic phase, 88 Wistar rats were used, distributed in two groups (inhaled and oral) and exposed for six months. Femoral bone marrow cells were collected for a micronucleus test and comet assay. Data were evaluated by pattern recognition algorithms. In acute exposure, medium and high concentrations induced DNA damage in the comet assay, but these concentrations did not increase micronucleated cells. In the chronic exposure, there was an increase in micronuclei and DNA damage in the comet assay in all exposed groups regardless of the exposure route. The data showed a robust pattern of distinction between exposed and nonexposed groups to 2,4-D. Our data showed that both acute inhalation exposure and chronic oral and inhalation exposure to 2,4-D can cause genotoxic effects regardless of concentration. Machine learning showed a clear distinction between the control groups and those exposed to 2,4-D, and the effects of exposure are not concentration-dependent.
\end{abstract}

Key words: Environmental health, Cancer, Pesticides exposure, Public health, Mutagenicity tests

\section{INTRODUCTION}

The 2,4-dichlorophenoxyacetic acid (2,4-D) herbicide is a synthetic auxin belonging to the group of phenoxyacetic acids developed during World War II with the aim of controlling broadleaf weeds (Sbano et al., 2013). 2,4-D is considered one of the most widely used herbicides in the world due to its low cost, high selectiveness, system- ic effects, ease of transport by the plant and inhibition of plant growth (Song, 2014).

Human exposure to pesticides represents a large public health problem due to the possible induction of mutations in genetic material (Siqueira et al., 2012).

The 2,4-D has been placed in group 2B (possibly carcinogenic to humans) by the International Agency for Research on Cancer (IARC) (IARC, 2015) and in group

Correspondence: Gisele Alborghetti Nai (E-mail: patologia@unoeste.br) 
D (not classifiable as to human carcinogenicity) by U.S. Environmental Protection Agency (US EPA) (RED, 2005). Genotoxicity to 2,4-D is controversial in the literature. A previous study has shown that breakage of the primary DNA strand in fish occurs after 7 days of exposure to 2,4-D (Ruiz de Arcaute et al., 2018). Other studies have shown that 2,4-D is not genotoxic and has no evidence of carcinogenicity in laboratory animals (Charles et al., 1999; Gollapudi et al., 1999; Bus and Hammond, 2007). However, the carcinogenicity of 2,4-D in humans has been widely debated due to the appearance of nonHodgkin's lymphoma in farmers using this herbicide (Hoar et al., 1986).

Machine learning has advanced considerably in recent years as it is a practical and broad technology (Burrel, 2016). The use of machine learning algorithms in the medical field has provided important results. This type of learning belongs to Artificial Intelligence because it is an automation process that generalizes the experience expressed in a set of data (Carvalho and Dallagassa, 2014).

Although there are several studies that have evaluated the genetic damage induced by pesticides in different experimental models, there is no data available for relevant concentrations to human exposures of the 2,4-D. In the present study, we adapted the environmental exposure of 2,4-D, using concentrations of exposure in crops, to assess the genotoxic effect of acute and chronic exposure to 2,4-D in rodent bone marrow cells. In addition, we evaluated the performance of machine learning algorithms in detecting differences in exposure groups through recognition performed from genotoxic characteristics.

\section{MATERIALS AND METHODS}

\section{Ethical approval of the study}

This study was approved by the Ethics Committee on the Use of Animals of the Universidade do Oeste Paulista (Protocols 3140 and 3761).

\section{Exposure to 2,4-dichlorophenoxyacetic acid (2,4-D)}

The animals were exposed to the 2,4-D (Nortox ${ }^{\circledR}$ SA, Arapongas, Paraná, Brazil) with the following composition: $806 \mathrm{~g} / \mathrm{L}$ dimethylamine salt of 2,4-dichlorophenoxyacetic $(80.6 \% \mathrm{~m} / \mathrm{v}), 670 \mathrm{~g} / \mathrm{L}$ 2,4-D acid equivalent $(67.0 \% \mathrm{~m} / \mathrm{v})$ and $424 \mathrm{~g} / \mathrm{L}$ inert ingredients $(42.4 \% \mathrm{~m} / \mathrm{v})$, and the concentration of total dioxins is $0.00001 \mathrm{~g} / \mathrm{kg}$ $(=0.01 \mathrm{ppm})$.

For each type of crop, a specific concentration of 2,4-D is required. The choice of doses was based on the lowest dose, the intermediate dose and the highest dose of 2,4-D used for spraying crops. Thus, the following concentrations were used based on the manufacturer's recommendation and adjusted to the size of the experimentation box to simulate the environmental exposure [12]: $3.71 \mathrm{x}$ $10^{-3}$ grams of active ingredient per hectare (g.a.i./ha) corresponding to $187.17 \mathrm{mg} / \mathrm{m}^{3}, 6.19 \times 10^{-3} \mathrm{~g}$.a.i./ha corresponding to $313.31 \mathrm{mg} / \mathrm{m}^{3}$ and $9.28 \times 10^{-3}$ g.a.i./ha corresponding to $467.93 \mathrm{mg} / \mathrm{m}^{3}$.

\section{Nebulization protocol}

For nebulization in the acute phase, 2,4-D was diluted in $10 \mathrm{~mL}$ of $0.9 \%$ sodium chloride solution $(\mathrm{NaCl})$, and for nebulization in the chronic phase, 2,4-D was diluted in $10 \mathrm{~mL}$ of distilled water (Mello et al., 2018).

The nebulization protocol had two boxes $(32 \times 24 \times 32$ $\mathrm{cm}$ ), and each box was coupled to an ultrasonic nebulizer (Pulmosonic Star ${ }^{\circledR}$, Soniclear Ind. Com. Imp. E Exp. Ltda., São Paulo, Brazil) (Mello et al., 2018). For simulation of an environmental exposure, holes were made manually in both boxes, allowing air to be exchanged between the internal and external environment of each box. The nebulization time was $15 \mathrm{~min}$ (time needed for the entire solution to be nebulized) per day.

\section{Animal protocol}

For acute exposure, 88 adult male Swiss mice (initial age of 60 days) were used and for chronic exposure, 88 adult male albino Wistar rats (initial age of 90 days) were used (El Kabbaoui et al., 2017).

The animals were placed in collective plastic cages measuring $30 \times 16 \times 19 \mathrm{~cm}$ and stored in a controlled environment (acclimatized vivarium) with photoperiods of $12 \mathrm{hr}$ of light and $12 \mathrm{hr}$ of darkness at an ambient temperature of $22 \pm 2^{\circ} \mathrm{C}$ (National Research Council, 2011). The animals received filtered water and balanced commercial feed (Supralab ${ }^{\circledR}$, Alisul, Brazil) ad libitum.

All groups were exposed at the same time in the acute and in the chronic phases.

\section{Design of acute exposure (inhalation only)}

The animals were randomly assigned to five groups as follows: $\mathrm{C}$ group (saline group), exposed to nebulization with $10 \mathrm{~mL}$ of sodium chloride solution $(0.9 \% \mathrm{NaCl})$ $(\mathrm{n}=20)$; BC group, exposed to nebulization with low concentration of 2,4-D ( $=20)$; MC group, exposed to nebulization with a mean concentration of 2,4-D $(n=20)$; AC group, exposed to nebulization with a high concentration of 2,4-D $(n=20)$; CPa group (positive control of acute exposure), exposed to cyclophosphamide (Genuxal, Baxter Oncology GmbH, Halle, Westfalen, Germany) in 
Genotoxicity of 2,4-dichlorophenoxyacetic

a single subcutaneous dose $(50 \mathrm{mg} / \mathrm{kg})$ on the first day of the experiment $(\mathrm{n}=8)$ (MacGregor et al., 1987).

The animals of groups $\mathrm{C}, \mathrm{BC}, \mathrm{MC}$ and $\mathrm{AC}$ were exposed repeatedly to nebulizations to the herbicide at different time intervals $(24,48$ and $72 \mathrm{hr})$ with 5 animals for 24 and $48 \mathrm{hr}$ and 10 animals for $72 \mathrm{hr}$. The animals were euthanized $24 \mathrm{hr}$ after the last nebulization, and five animals nebulized three times were euthanized $192 \mathrm{hr}$ after the last nebulization (Mello et al., 2018) (Fig. 1). The animals in the CPa group were euthanized $24 \mathrm{hr}$ after the beginning of the experiment (MacGregor et al., 1987).

\section{Design of chronic exposure (inhalation and oral exposure)}

The animals were randomly divided into two major groups, namely, inhalation exposure and oral exposure, with respective subgroups (Table 1).

The CPc group (positive control of chronic exposure) was exposed to cyclophosphamide (Genuxal, Baxter Oncology $\mathrm{GmbH}$ ) in a single subcutaneous dose $(50 \mathrm{mg} / \mathrm{kg})$ on the first day of the experiment $(\mathrm{n}=8)$ (MacGregor et al., 1987).

The animals exposed by inhalation were nebulized for five days in a week to simulate the occupational exposure of the rural worker. The feed of the animals in the oral group was nebulized one day before being offered to them, being changed every two days. The residual feed was weighed at each change.

Animals in all chronic exposure groups were exposed for 6 months and then euthanized $24 \mathrm{hr}$ after the last nebulization. The animals in the $\mathrm{CPc}$ group were euthanized $24 \mathrm{hr}$ after the beginning of the experiment (MacGregor et al., 1987).

Euthanasia of all animals (acute and chronic exposure)
Table 1. Study groups evaluated with chronic exposure.

\begin{tabular}{lccc}
\hline Exposure intensity & $\begin{array}{c}\text { Inhalation } \\
\text { exposure }\end{array}$ & $\begin{array}{c}\text { Oral } \\
\text { exposure }\end{array}$ & Sample \\
\hline Control & CI & CO & $\mathrm{n}=10 /$ group \\
Low concentration & BCI & BCO & $n=10 /$ group \\
Medium concentration & MCI & MCO & $n=10 /$ group \\
High concentration & ACI & ACO & $n=10 /$ group \\
\hline
\end{tabular}

CI: inhalation control group; $\mathrm{CO}$ : oral control group; $\mathrm{BCI}$ : inhalation low 2,4-D concentration group; $\mathrm{BCO}$ : oral low concentration group; MCI: inhalation medium concentration group; MCO: oral medium concentration group; ACI: inhalation high concentration group; ACO: oral high concentration group.

was performed with sodium thiopental (Syntec, Santana do Parnaíba, SP, Brazil) at a dose of $100 \mathrm{mg} / \mathrm{kg}$ of weight administered in the peritoneal cavity (Paiva et al., 2005; National Research Council, 2011).

\section{Micronucleus test}

For the micronucleus test, bone marrow material was collected from one of the femurs of each animal at the time of euthanasia, and two slides per animal were prepared (MacGregor et al., 1987). Slides were stained with Giemsa stain (Dolles, São Paulo, Brazil). To determine the number of micronuclei, 2000 polychromatic erythrocytes were counted per animal using an optical microscope at 400x magnification (MacGregor et al., 1987). Micronuclei were characterized according to Tolbert et al. (1992). The analysis of the slides was blind and performed by one researcher (GAN).

\section{Comet assay}

Bone marrow samples were collected from a femur of each animal. Cells were resuspended in storage medium composed of fetal bovine serum (Cultilab, São Paulo,

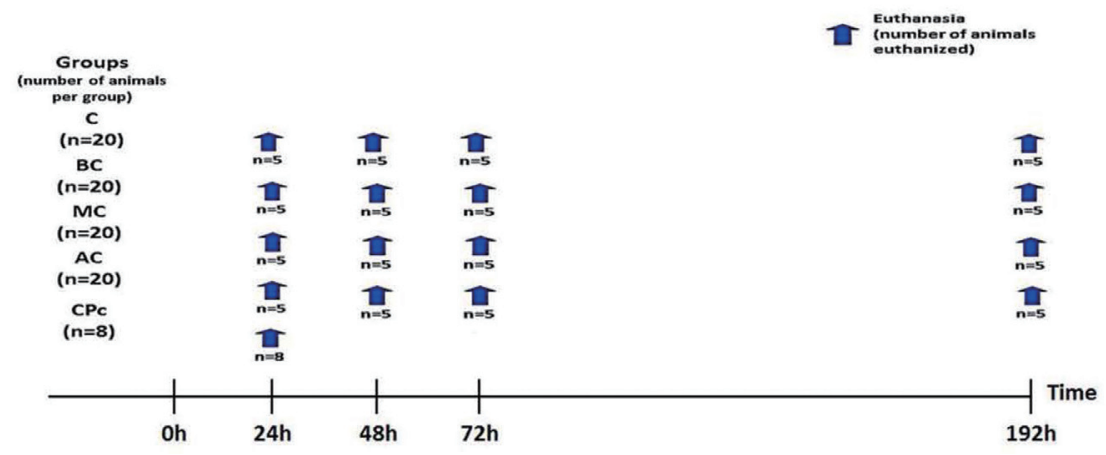

Fig. 1. Design of acute exposure. C: saline group; BC: low 2,4-D concentration group; MC: middle 2,4-D concentration group; $\mathrm{AC}$ : high 2,4-D concentration group; $\mathrm{CPa}$ : positive control of acute exposure. 
SP, Brazil), RPMI 1640 medium (Sigma, San Luis, MO, USA) and dimethyl sulfoxide (DMSO; Merck, Darmstadt, Germany), and they were stored at $-80^{\circ} \mathrm{C}$.

After defrosting the sample, for viability analysis, $10 \mu \mathrm{L}$ of the bone marrow cell solution was mixed with $10 \mu \mathrm{L}$ of trypan blue (Thermo Scientific, South Loga, UT, USA) and 200 cells were analyzed per treatment. The minimum recommended bioavailability for Comet assay is $75 \%$ (Singh et al., 1988).

Slides were prepared, placed in a horizontal electrophoresis chamber, covered with electrophoresis buffer, and incubated for $20 \mathrm{~min}$. Electrophoresis was then performed in alkaline conditions $(\mathrm{pH}>13)$ at $25 \mathrm{~V}$ and a current of $300 \mathrm{~mA}$ for one hour. After electrophoresis, samples were neutralized with Tris buffer (Tris $0.4 \mathrm{M}$; $\mathrm{pH}$ 7.5). Subsequently, slides were placed in a fixative solution [containing trichloroacetic acid, zinc sulfate (heptahydrate) and glycerol] and then washed. Samples were then stained in a silver solution at $37^{\circ} \mathrm{C}$ and stirred until the solution started to darken. Slides were then washed and placed in a stop solution for five minutes and washed again. After this process, slides were dried at room temperature and covered with a coverslip for analysis (Scherer and Strohschoen, 2013).

One hundred cells from each animal were chosen at random and analyzed under an optical microscope with 400x magnification. Cells were classified according to the shape and size of the tail into four classes of DNA damage as follows: 0 (no damage), 1, 2, 3 and 4 (highest degree of damage). "Hedgehog" cells were excluded from analysis (Villela et al., 2006). The analysis of the slides was blind and performed by one researcher (FMA).

\section{Statistical analysis}

Because the variables did not show normality by the Kolmogorov-Smirnov test or homogeneity of variances by the Levene test, the Kruskal-Wallis test was applied followed by the Dunn test for multiple comparisons.

SPSS V. 23 software was used, and the level of significance used for each test was $5 \%$.

\section{Machine learning algorithms}

The machine learning analysis experiments were performed as described by Tomiazzi et al. (2018).

To evaluate the hypothesis that acute and chronic exposure to 2,4-D causes a genotoxic effect on bone marrow cells, machine learning algorithms were used. Pattern recognition was performed based on the following genotoxic characteristics: (a) comets and (AA) micronuclei. The hypothesis was confirmed if the classification algorithm indicated the group (control or exposure) according to the parameters presented in each group.

The confusion or classification matrix was created from a set of data divided into categories, which determined whether the expected values correspond to the real value, with the total of these results displayed in a matrix.

The classification algorithms learned from a first set of examples, in which the group was previously known, which is called a training set. In this set, the algorithms are responsible for identifying the different types that can be used to complete the classification task. After training, the samples that were obtained by the algorithms and by the real group were tested. The hypothesis was proven if the methods used for the classification identified the groups with high precision.

For computational experiments, the following five versions of the collected dataset were considered:

- Dataset1: Groups subjected to acute exposure (C, BC, $\mathrm{MC}, \mathrm{AC}$ and $\mathrm{CPa}$ ) in the micronucleus test and in the comet assay.

- Dataset2: Groups subjected to acute exposure (C, $\mathrm{BC}+\mathrm{MC}+\mathrm{AC}$ and $\mathrm{CPa}$ ) in the micronucleus test and in the comet assay.

- Dataset3: Groups subjected to chronic exposure (CI, $\mathrm{CO}, \mathrm{BCI}, \mathrm{BCO}, \mathrm{MCI}, \mathrm{MCO}, \mathrm{ACI}, \mathrm{ACO}$ and $\mathrm{CPc}$ ) in the micronucleus test and the comet test.

- Dataset4: Groups subjected to chronic exposure (CI, $\mathrm{CO}, \mathrm{BCI}+\mathrm{MCI}+\mathrm{ACI}, \mathrm{BCO}+\mathrm{MCO}+\mathrm{ACO}$ and $\mathrm{CPc})$ in the micronucleus test and in the comet assay.

- Dataset5: Groups subjected to chronic exposure $(\mathrm{CI}+\mathrm{CO}, \mathrm{BCI}+\mathrm{MCI}+\mathrm{ACI}+\mathrm{BCO}+\mathrm{MCO}+\mathrm{ACO}$ and $\mathrm{CPc})$ in the micronucleus test and the comet assay.

For the size of each training set and each dataset, 20 runs were performed. All experiments were performed on a computer with an Intel i5 6500U processor with 8 GB of RAM using Linux as the operating system. The samples and test sets were part of a set of resources that outlined the measurements of mice and rats, and they were labeled according to their respective classes $(\mathrm{C}$, $\mathrm{BC}, \mathrm{MC}, \mathrm{AC}, \mathrm{CPa}, \mathrm{CI}, \mathrm{BCI}, \mathrm{MCI}, \mathrm{ACI}, \mathrm{CO}, \mathrm{BCO}, \mathrm{MCO}$, $\mathrm{ACO}$ and $\mathrm{CPc}$ ). Five different sizes of training sets were used $(50,60,70,80$ and $90 \%)$ with the aim of investigating the learning rate of the classification algorithms and datasets of all training sets and remaining tests.

\section{Classification algorithms}

\section{K-Nearest neighbors}

The first machine learning algorithm used in computational analysis was the k-Nearest Neighbors (k-NN). $\mathrm{k}-\mathrm{NN}$ is a simple and effective technique, and it is known for making use of all samples, which were used for training as a prototype through the input parameter $\mathrm{k}$. The clas- 
Genotoxicity of 2,4-dichlorophenoxyacetic

sification of a sample is achieved considering the nearest $\mathrm{k}$ training samples. For the value of $\mathrm{k}=1$, the test sample ends up being classified according to the class of the training sample that is closest to it (Pereira et al., 2018).

\section{Support vector machine}

The second machine learning algorithm used in computational analysis was the support vector machine (SVM) approach, which is based on the reduction of structural risks (Vapnik, 1999). The objective of SVM is to establish a function that discriminates between two classes of standards. During the analysis of the results, the kernel used was the Radical Base Function (RBF). The SIGMA and $\mathrm{C}$ parameters were determined using a grid search in the interval $\left[2^{-15}, 2^{15}\right]$ with a power step of 2 .

\section{Decision Tree}

The third machine learning algorithm used in computational analysis was the Decision Tree (DT). This model uses a decision tree with possible results, including accidental ones. This algorithm is commonly used in operational research, with emphasis on decision analysis, to find strategies that reach the goal with greater probability.

\section{Metrics}

In the context of this work, we used accuracy as a performance metric. Given a set with $\mathrm{n}$ test samples, we calculated the accuracy (Acc) as follows: Acc = hits / n, where hits denote the amount of correct ratings.

\section{Training data sets}

The training data sets ranged from 0 (zero) to 90 (ninety), that is, the matrices are equivalent to $90 \%$. Therefore,

Table 2. Minimum and maximum number of micronuclei in each group by time of exposure with acute exposure.

\begin{tabular}{lcccc}
\hline \multirow{2}{*}{ Groups } & \multicolumn{4}{c}{ Exposure time } \\
\cline { 2 - 5 } & $24 \mathrm{hr}$ & $48 \mathrm{hr}$ & $72 \mathrm{hr}$ & $192 \mathrm{hr}$ \\
\hline $\mathrm{C}$ & $0-0^{\mathrm{Aa}}$ & $0-0^{\mathrm{Aa}}$ & $0-0^{\mathrm{Aa}}$ & $0-1^{\mathrm{Aa}}$ \\
$\mathrm{BC}$ & $0-3^{\mathrm{Aa}}$ & $0-0^{\mathrm{Aa}}$ & $0-1^{\mathrm{Aa}}$ & $0-1^{\mathrm{Aa}}$ \\
$\mathrm{MC}$ & $0-3^{\mathrm{Aa}}$ & $0-0^{\mathrm{Aa}}$ & $0-3^{\mathrm{Aa}}$ & $0-1^{\mathrm{Aa}}$ \\
$\mathrm{AC}$ & $0-3^{\mathrm{Aa}}$ & $0-2^{\mathrm{Aa}}$ & $1-5^{\mathrm{Aa}}$ & $0-2^{\mathrm{Aa}}$ \\
$\mathrm{CPa}$ & \multicolumn{4}{c}{$7-15^{\mathrm{B}, \mathrm{b}}$} \\
\hline
\end{tabular}

$\mathrm{C}$ : saline group; $\mathrm{BC}$ : low 2,4-D concentration group; $\mathrm{MC}$ : middle 2,4-D concentration group; AC: high 2,4-D concentration group; CPa: positive control of acute exposure. Capital letters compare the same group in the same line. Lower case letters compare groups at the same time and in the same column. Different letters means $p$-value $<0.05$, where: $\mathrm{A} \neq \mathrm{B}$; and $\mathrm{a} \neq \mathrm{b}$. the number of training data sets is equal to 90 times the size of the data set.

The parameters used in the experiments were defined empirically, they are: for the K-NN classifier we used the number of neighbors as 3; for the SVM we used the RBF kernel and gamma as 2 and $\mathrm{C}$ as 1; and for Decision Tree we used the maximum depth as 5 .

\section{RESULTS}

\section{Acute exposure}

\section{Micronucleus test}

The median micronuclei in the negative control group (C), $\mathrm{BC}$ group, $\mathrm{MC}$ group, $\mathrm{AC}$ group and $\mathrm{CPa}$ (positive control) groups was $0,0,0,1$ and 11.5 , respectively. There was a difference between the groups studied $(\mathrm{p}<0.0001)$ and when the $\mathrm{CPa}$ group was compared to the $\mathrm{C}, \mathrm{BC}, \mathrm{MC}$ and $\mathrm{AC}$ groups $(\mathrm{p}<0.05)$, but there was no difference regarding the exposure times $(\mathrm{p}>0.05)$ (Table 2, Fig. 2).

\section{Comet assay}

The minimum bioavailability of $86 \%$ was verified in the samples.

Regarding cells with a score of 0 , there was a difference between the $\mathrm{C}$ group and the $\mathrm{MC}, \mathrm{AC}$ and $\mathrm{CPa}$ groups as well as between the $\mathrm{BC}$ group and the $\mathrm{MC}, \mathrm{AC}$ and $\mathrm{CPa}$ groups $(\mathrm{p}<0.0001)$. Regarding cells with a score of 1 ,

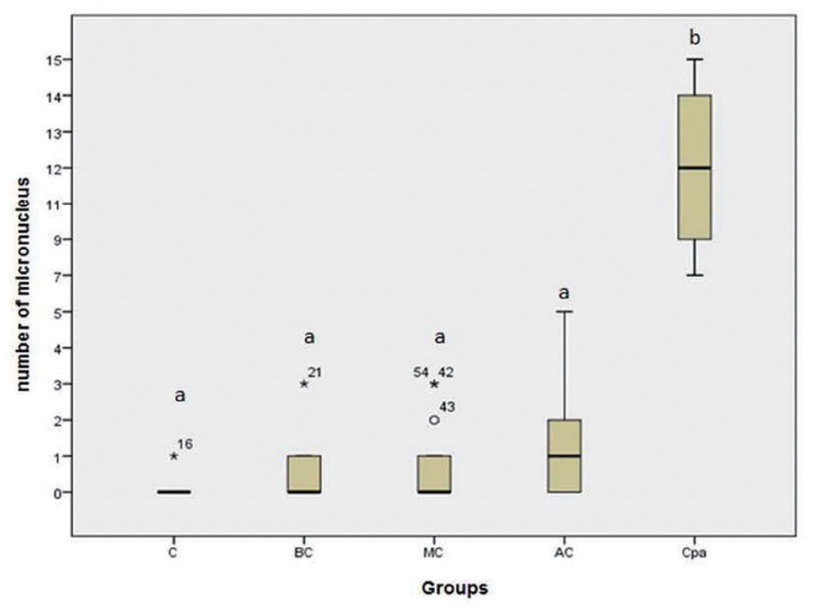

Fig. 2. Micronucleus count per study group regardless of exposure time (median and interquartile range) with acute exposure. C: saline group; BC: low 2,4-D concentration group; $\mathrm{MC}$ : middle 2,4-D concentration group; AC: high 2,4-D concentration group; $\mathrm{CPa}$ : positive control of acute exposure. a x b: p-value $<0,0001$ (Dunn test). 
there was no difference between groups $(p=0.2013)$. The number of cells showing a score pf 2 differed between the $\mathrm{BC}$ and MC groups $(\mathrm{p}=0.0180)$. Regarding cells with a score of 3 , there was a difference between the $\mathrm{C}$ group and the $\mathrm{MC}$ and $\mathrm{AC}$ groups as well as the $\mathrm{BC}$ group and $\mathrm{AC}$ group ( $p<0.0001)$. For cells with a score of 4 , there was a difference between the $\mathrm{C}$ group and the $\mathrm{MC}, \mathrm{AC}$ and $\mathrm{CPa}$ groups as well as the $\mathrm{BC}$ group and the $\mathrm{MC}, \mathrm{AC}$ and $\mathrm{CPa}$ groups $(\mathrm{p}<0.0001)$. There was a difference in relation to the exposure times only for cells with a score of 2 with an increase in the number of cells with a score of 2 for the control group and for groups exposed after $192 \mathrm{hr}$ compared to the control groups and groups exposed for 24 and $48 \mathrm{hr}(\mathrm{p}<0.001)$ (Table 3 and Fig. 3).

\section{Chronic exposure}

\section{Feed consumption}

There was no difference in feed intake between exposed and unexposed groups $(\mathrm{p}>0.05)$.

\section{Micronucleus test}

The median micronuclei in the inhaled control $(\mathrm{CI})$, oral control (CO), BCI, BCO, MCI, MCO, ACI, ACO and $\mathrm{CPc}$ (positive control) groups was $0,0,1.5,3,4,6$, 5,5 and 9 , respectively. Figure 4 shows that the following groups had differences $(\mathrm{p}<0.0001)$ : between the $\mathrm{CI}$ group and the $\mathrm{ACI}$ and $\mathrm{CPc}$ groups; between the $\mathrm{CO}$ group and the $\mathrm{MCO}, \mathrm{ACO}$ and $\mathrm{CPc}$ groups; and between the $\mathrm{CPc}$ group and the $\mathrm{BCI}$ and $\mathrm{BCO}$ groups. There was no difference between the routes of exposure (oral and inhaled) $(\mathrm{p}>0.05)$.

\section{Comet assay}

The minimum bioavailability of $90 \%$ was verified in the samples.

Regarding cells with a score of 0 , the following groups showed differences $(p<0.0001)$ : between the CI group and the $\mathrm{MCI}$ and $\mathrm{ACI}$ groups; between the $\mathrm{CO}$ group and the $\mathrm{MCO}$ and $\mathrm{ACO}$ groups; between the $\mathrm{BCO}$ and $\mathrm{MCO}$ groups; and between the $\mathrm{CPc}$ group and the MCO, ACI and ACO groups. Regarding cells with a score of 1 , the following groups showed differences $(p<0.0001)$ : between the CI and ACI groups; between the BCI and $\mathrm{ACI}$ groups; between the $\mathrm{BCO}$ groups and the $\mathrm{MCO}$ and ACO groups; and between the CPc group and the ACI and ACO groups. Regarding cells with a score of 2, there was a difference between the $\mathrm{CI}$ and ACI groups as well as between the $\mathrm{CO}$ group and the $\mathrm{ACO}$ and $\mathrm{CPc}$ groups $(p<0.0001)$. For cells with a score of 3 , the following groups showed differences $(\mathrm{p}<0.0001)$ : between the CI group and the MCI and ACI groups; between the $\mathrm{CO}$ group and the $\mathrm{MCO}$ and $\mathrm{ACO}$ groups; and between the $\mathrm{BCO}$ group and the MCO and ACO groups. For cells with a score or 4, the following groups showed differences ( $<<0.0001)$ : between the CO group and the MCO and $\mathrm{ACO}$ groups; between the $\mathrm{BCO}$ and $\mathrm{MCO}$ groups; and between the $\mathrm{CPc}$ groups and the $\mathrm{MCO}$ and $\mathrm{ACO}$ groups. There was no difference between the routes of exposure (oral and inhaled) $(\mathrm{p}>0.05)$ (Fig. 5).

\section{Machine learning}

Confusion matrix analyses were performed individually according to the following genotoxic characteristics: comet and micronucleus (Supplemental data). Different machine learning algorithms (k-NN, SVM and DT) were used due to the accuracy of the training sample size

Table 3. Minimum and maximum number of cells for each comet assay score in each group by exposure time with acute exposure.

\begin{tabular}{|c|c|c|c|c|c|}
\hline \multirow{2}{*}{ Groups } & \multirow{2}{*}{ Score } & \multicolumn{4}{|c|}{ Exposure time } \\
\hline & & $24 \mathrm{hr}$ & $48 \mathrm{hr}$ & $72 \mathrm{hr}$ & $192 \mathrm{hr}$ \\
\hline \multirow{5}{*}{$\mathrm{C}$} & Escore 0 & $41-96^{\mathrm{A}}$ & $9-85^{\mathrm{A}}$ & $5-39^{\mathrm{B}}$ & $15-78^{\mathrm{A}}$ \\
\hline & Escore 1 & $3-57^{\mathrm{A}}$ & $5-53^{A}$ & $4-32^{\mathrm{A}}$ & $4-26^{\mathrm{A}}$ \\
\hline & Escore 2 & $0-2^{\mathrm{A}}$ & $5-16^{\mathrm{B}}$ & $6-21^{\mathrm{B}}$ & $4-35^{\mathrm{B}}$ \\
\hline & Escore 3 & $0-0^{\mathrm{A}}$ & $1-17^{\mathrm{B}}$ & $7-30^{\mathrm{B}}$ & $6-26^{\mathrm{B}}$ \\
\hline & Escore 4 & $0-0^{\mathrm{A}}$ & $0-62^{\mathrm{B}}$ & $17-55^{\mathrm{B}}$ & $8-26^{\mathrm{C}}$ \\
\hline \multirow{5}{*}{$\mathrm{BC}$} & Escore 0 & $2-94^{\mathrm{A}}$ & $19-87^{\mathrm{A}}$ & $15-40^{\mathrm{A}}$ & $5-27^{\mathrm{B}}$ \\
\hline & Escore 1 & $1-19^{A}$ & $2-28^{A}$ & $7-20^{\mathrm{A}}$ & $13-38^{\mathrm{A}}$ \\
\hline & Escore 2 & $1-15^{\mathrm{A}}$ & $2-13^{A}$ & $5-14^{\mathrm{A}}$ & $2-30^{\mathrm{A}}$ \\
\hline & Escore 3 & $1-29^{A}$ & $3-16^{A}$ & $12-25^{\mathrm{A}}$ & $2-27^{\mathrm{A}}$ \\
\hline & Escore 4 & $1-55^{\mathrm{A}}$ & $6-31^{A}$ & $31-50^{\mathrm{A}}$ & $5-43^{A}$ \\
\hline \multirow{5}{*}{$\mathrm{MC}$} & Escore 0 & $1-20^{\mathrm{A}}$ & $0-13^{\mathrm{A}}$ & $2-24^{\mathrm{A}}$ & $1-10^{\mathrm{A}}$ \\
\hline & Escore 1 & $1-32^{\mathrm{A}}$ & $4-30^{\mathrm{A}}$ & $10-26^{\mathrm{A}}$ & $9-21^{\mathrm{A}}$ \\
\hline & Escore 2 & $12-18^{\mathrm{A}}$ & $10-16^{\mathrm{A}}$ & $8-25^{\mathrm{A}}$ & $17-25^{\mathrm{A}}$ \\
\hline & Escore 3 & $7-27^{\mathrm{A}}$ & $9-27^{\mathrm{A}}$ & $16-27^{\mathrm{A}}$ & $14-23^{\mathrm{A}}$ \\
\hline & Escore 4 & $35-66^{\mathrm{A}}$ & $36-60^{A}$ & $26-48^{\mathrm{A}}$ & $35-47^{\mathrm{A}}$ \\
\hline \multirow{5}{*}{$\mathrm{AC}$} & Escore 0 & $1-17^{\mathrm{A}}$ & $2-5^{\mathrm{A}}$ & $2-11^{\mathrm{A}}$ & $1-5^{\mathrm{A}}$ \\
\hline & Escore 1 & $0-34^{\mathrm{A}}$ & $4-20^{A}$ & $5-19^{A}$ & $3-9^{\mathrm{B}}$ \\
\hline & Escore 2 & $0-26^{\mathrm{A}}$ & $5-12^{\mathrm{A}}$ & $7-39^{A}$ & $12-39^{\mathrm{A}}$ \\
\hline & Escore 3 & $1-42^{\mathrm{A}}$ & $12-22^{\mathrm{A}}$ & $17-27^{\mathrm{A}}$ & $25-33^{\mathrm{A}}$ \\
\hline & Escore 4 & $19-98^{\mathrm{A}}$ & $48-68^{\mathrm{A}}$ & $23-62^{\mathrm{A}}$ & $30-48^{\mathrm{A}}$ \\
\hline \multirow{5}{*}{$\mathrm{CPa}$} & Escore 0 & \multicolumn{4}{|c|}{$32-44$} \\
\hline & Escore 1 & \multicolumn{4}{|c|}{$8-27$} \\
\hline & Escore 2 & \multicolumn{4}{|c|}{$17-27$} \\
\hline & Escore 3 & \multicolumn{4}{|c|}{$11-21$} \\
\hline & Escore 4 & \multicolumn{4}{|c|}{$8-13$} \\
\hline
\end{tabular}

$\mathrm{C}$ : saline group; $\mathrm{BC}$ : low 2,4-D concentration group; MC: middle 2,4-D concentration group; AC: high 2,4-D concentration group; CPa: positive control of acute exposure. Capital letters compare the same group in the same line. Different letters means p-value $<0.05$, where: $\mathrm{A} \neq \mathrm{B}$. 
Genotoxicity of 2,4-dichlorophenoxyacetic
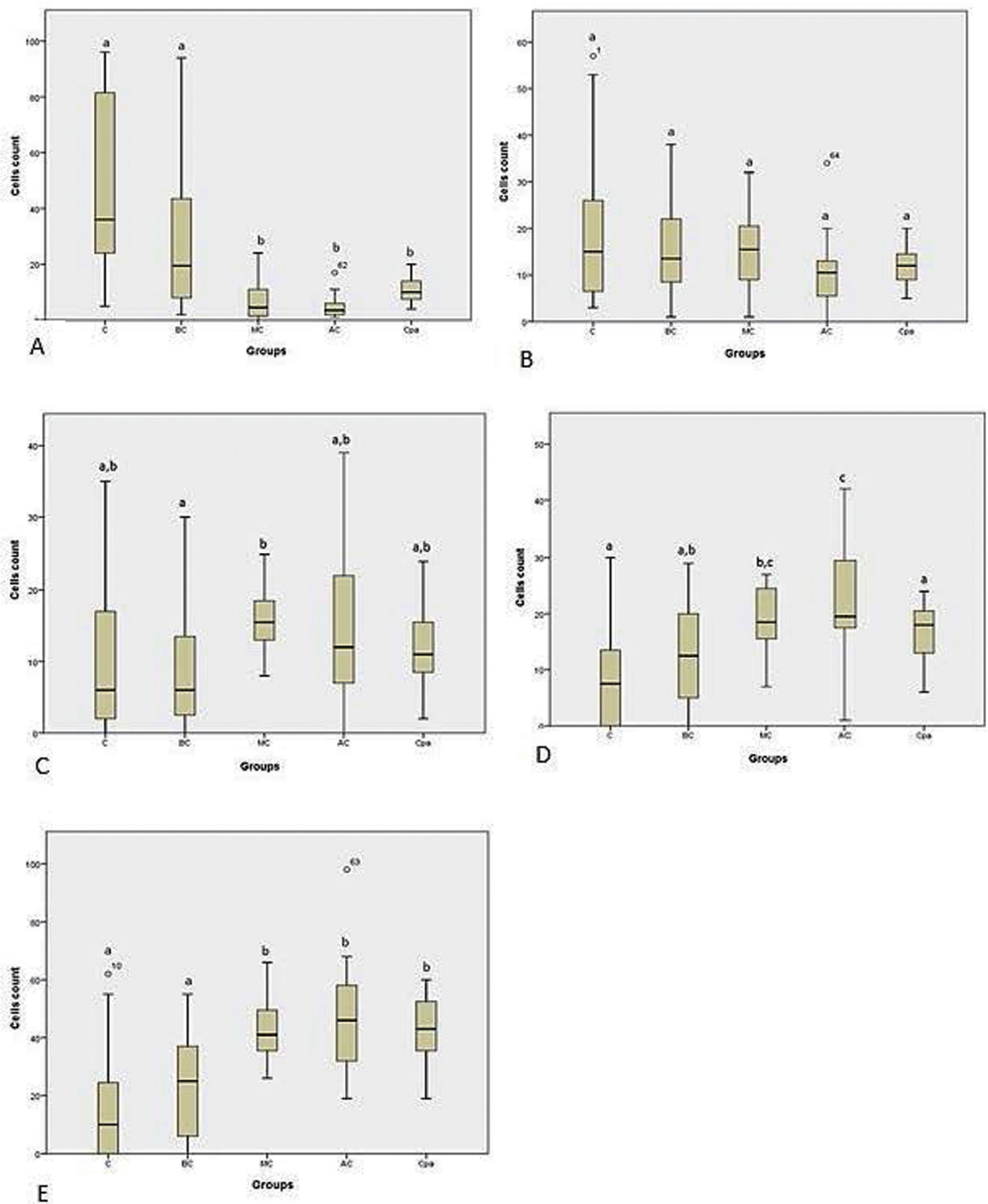

Fig. 3. Comet assay with acute exposure. A - Number of cells with a score of 0 in each study group regardless of exposure time (a x b: p-value $<0,0001$ - Dunn test). B - Number of cells with a score of 1 in each study group regardless of exposure time ( $\mathrm{a}$ x b: $\mathrm{p}$-value $=0.2013$ - Dunn test). $\mathrm{C}$ - Number of cells with a score of 2 in each study group regardless of exposure time ( $\mathrm{x}$ b: p-value $=0,0180$ - Dunn test). D - Number of cells with a score of 3 in each study group regardless of exposure time ( $\mathrm{a} \times \mathrm{b}$ and $\mathrm{b} \times \mathrm{c}$ : p-value $<0,0001$ - Dunn test). E - Number of cells with a score of 4 in each study group regardless of exposure time ( $\mathrm{a}$ x b: $\mathrm{p}$-value <0,0001 - Dunn test). C: saline group; BC: low 2,4-D concentration group; MC: middle 2,4-D concentration group; $\mathrm{AC}$ : high 2,4-D concentration group; $\mathrm{CPa}$ : positive control of acute exposure. ${ }^{\circ}$ : outlier and animal number. 


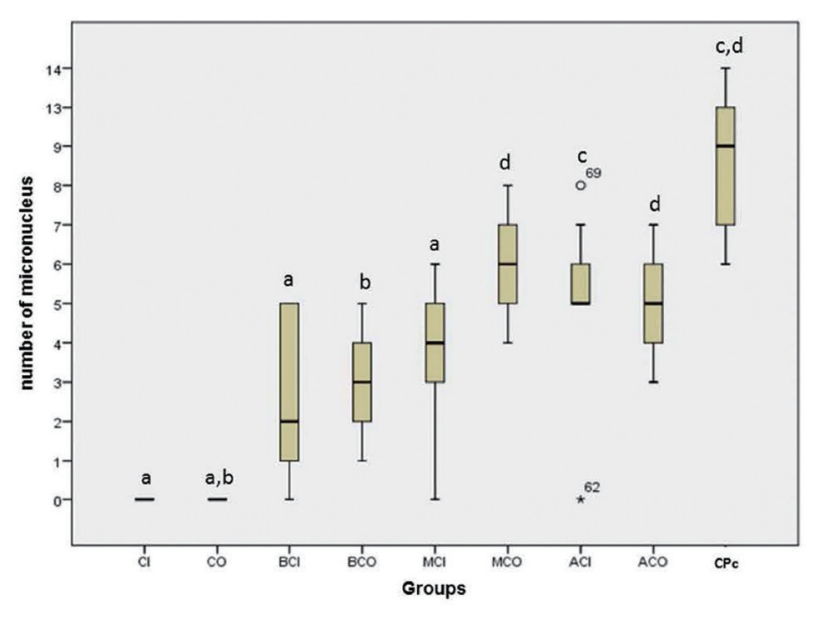

Fig. 4. Count of micronuclei per study group (median and interquartile range) with chronic exposure. CI: inhalation control group; CO: oral control group; BCI: inhalation low 2,4-D concentration group; BCO: oral low concentration group; MCI: inhalation medium concentration group; MCO: oral medium concentration group; $\mathrm{ACI}$ : inhalation high concentration group; ACO: oral high concentration group; CPc: positive control of chronic exposure. ${ }^{\circ}, *$ : outlier and animal number. a x c and b x d: p-value $<0,0001-$ (Dunn test).

effect. The DT algorithm was selected for the analysis and construction of the confusion matrix in most datasets as it was the one with the best values in relation to the size effect of the training sample (accuracy oscillated between 40 and $80 \%$ ) (Fig. 6).

\section{Acute exposure}

Table 4 lists the confusion matrix for Dataset1 where reasonable accuracy was observed for group C (56\%).

Table 4. Confusion matrix regarding the classification of Dataset1 with five classes $(\mathrm{C}, \mathrm{BC}, \mathrm{MC}, \mathrm{AC}$ and $\mathrm{CPa}$ ) using DT and $80 \%$ of the samples for the training set.

\begin{tabular}{lccccc}
\hline \multirow{2}{*}{ True class (\%) } & \multicolumn{5}{c}{ Classified as (\%) } \\
\cline { 2 - 6 } & $\mathrm{C}$ & $\mathrm{BC}$ & $\mathrm{MC}$ & $\mathrm{AC}$ & $\mathrm{CPa}$ \\
\hline $\mathrm{C}$ & $\mathbf{5 6}$ & 26 & 8 & 9 & 0 \\
$\mathrm{BC}$ & 30 & $\mathbf{2 9}$ & 19 & 22 & 0 \\
$\mathrm{MC}$ & 7 & 9 & $\mathbf{7 3}$ & 11 & 0 \\
$\mathrm{AC}$ & 6 & 21 & 25 & $\mathbf{4 7}$ & 0 \\
$\mathrm{CPa}$ & 0 & 4 & 1 & 0 & $\mathbf{9 5}$ \\
\hline
\end{tabular}

$\mathrm{C}$ : saline group; $\mathrm{BC}$ : low 2,4-D concentration group; $\mathrm{MC}$ : middle 2,4-D concentration group; AC: high 2,4-D concentration group; CPa: positive control of acute exposure. DT: Decision Tree.
This conclusion occurred due to the 5 classes present in the analyzed dataset $(\mathrm{C}, \mathrm{BC}, \mathrm{MC}, \mathrm{AC}$ and $\mathrm{CPa})$ where a random classification process would have an accuracy of approximately $20 \%(100 \% / 5$ classes $=20 \%)$. The BC class presented low accuracy $(29 \%)$, and the MC class presented very good accuracy $(73 \%)$. The AC class presented reasonable accuracy (47\%), and CPa showed excellent accuracy $(95 \%)$.

Regarding the experiment setup for Dataset2 (Table 5), very good accuracy was observed for $\mathrm{BC}+\mathrm{MC}+\mathrm{AC}$ (81\%). A random classification was demonstrated around an accuracy of approximately $33.33 \%$. As a result, class C presented reasonably low accuracy (47\%), and CPa presented excellent accuracy (93\%).

\section{Chronic exposure}

In Dataset3, k-NN was used as this algorithm presented the best value in relation to the training sample size effect (accuracy oscillated between 40 and 60\%) (Fig. 7).

Excellent accuracy was noted in CO (100\%) and CI $(84 \%)$. A random classification was demonstrated around an accuracy of approximately $11.11 \%$. The BCI (67\%), BCO (57\%) and ACI (55\%) classes showed reasonable accuracy. The MCI (17\%), MCO (24\%) and ACO (15\%) classes showed reasonably low accuracy, and CPc showed excellent accuracy (100\%) (Table 6).

Regarding the confusion matrix for Dataset4, there was excellent accuracy in CO (100\%) and very good accuracy in $\mathrm{CI}(88 \%)$ and $\mathrm{CPc}(85 \%)$. The $\mathrm{BCI}+\mathrm{MCI}+\mathrm{ACI}(64 \%)$ and $\mathrm{BCO}+\mathrm{MCO}+\mathrm{ACO}(61 \%)$ classes showed good accuracy (Table 7).

When analyzing the data in isolation, the $\mathrm{BCI}+\mathrm{MCI}+\mathrm{ACI}$ and $\mathrm{BCO}+\mathrm{MCO}+\mathrm{ACO}$ classes showed confusion between them. Thus, a grouped analysis was performed as shown in

Table 5. Confusion matrix regarding the classification of Dataset2 with three classes $(\mathrm{C}, \mathrm{BC}+\mathrm{MC}+\mathrm{AC}$ and $\mathrm{CPa}$ ) using DT and $80 \%$ of the samples for the training set.

\begin{tabular}{lccc}
\hline \multirow{2}{*}{ True class (\%) } & \multicolumn{3}{c}{ Classified as (\%) } \\
\cline { 2 - 4 } & $\mathrm{C}$ & $\mathrm{BC}+\mathrm{MC}+\mathrm{AC}$ & $\mathrm{CPa}$ \\
\hline $\mathrm{C}$ & $\mathbf{4 7}$ & 53 & 0 \\
$\mathrm{BC}+\mathrm{MC}+\mathrm{AC}$ & 19 & $\mathbf{8 1}$ & 0 \\
$\mathrm{CPa}$ & 0 & 7 & $\mathbf{9 3}$ \\
\hline
\end{tabular}

C: saline group; $\mathrm{BC}$ : low 2,4-D concentration group; $\mathrm{MC}$ : middle 2,4-D concentration group; AC: high 2,4-D concentration group; $\mathrm{CPa}$ : positive control of acute exposure. DT: Decision Tree. 
Genotoxicity of 2,4-dichlorophenoxyacetic
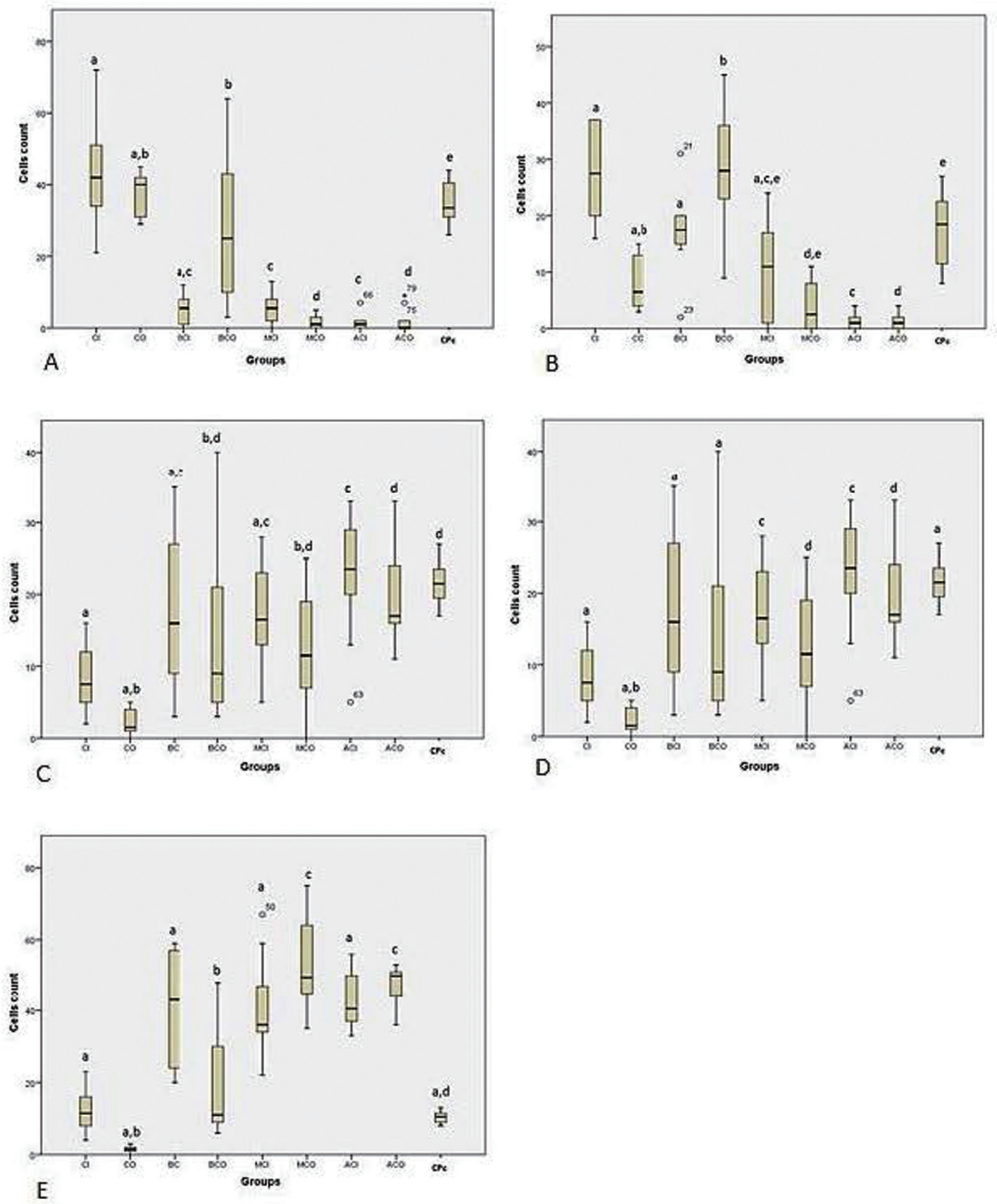

Fig. 5. Comet assay with chronic exposure. A - Number of cells with a score of 0 in each study group regardless of exposure time ( $\mathrm{x}$ x c; b x d; and c, d x e: p-value $<0,0001$ - Dunn test). B - Number of cells with a score of 1 in each study group regardless of exposure time ( $\mathrm{x}$ c; b x d; and c, $d \times$ e: p-value $<0,0001$ - Dunn test). C - Number of cells with a score of 2 in each study group regardless of exposure time ( $\mathrm{x} \mathrm{c}$ and $\mathrm{b} \times \mathrm{d}$ : $\mathrm{p}$-value $<0,0001$ - Dunn test). D - Number of cells with a score of 3 in each study group regardless of exposure time (a x c and b x d: p-value $<0,0001$ - Dunn test). E - Number of cells with a score of 4 in each study group regardless of exposure time (b x c and c x d: p-value $<0,0001$ - Dunn test). CI: inhalation control group; $\mathrm{CO}$ : oral control group; $\mathrm{BCI}$ : inhalation low 2,4-D concentration group; BCO: oral low concentration group; MCI: inhalation medium concentration group; MCO: oral medium concentration group; ACI: inhalation high concentration group; ACO: oral high concentration group; $\mathrm{CPc}$ : positive control of chronic exposure. ${ }^{\circ}$,: outlier and animal number. 


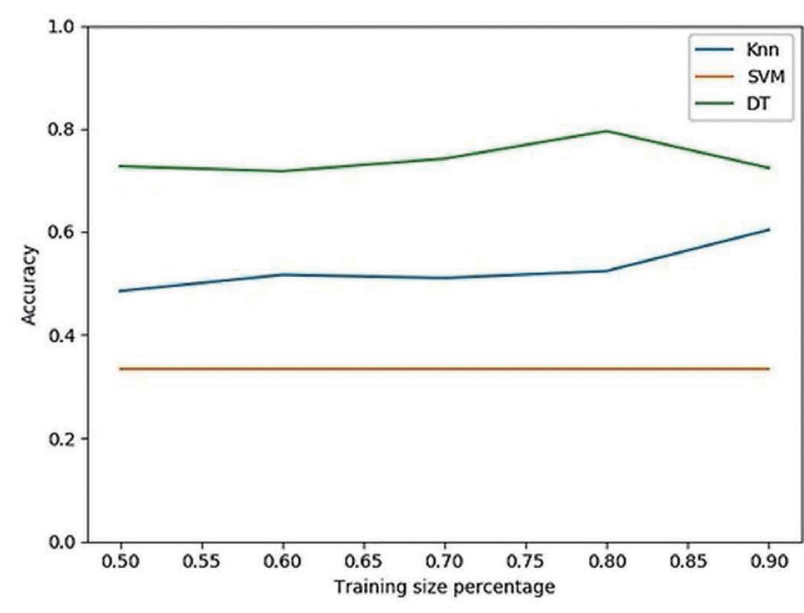

Fig. 6. Accuracy of classification and different sizes of the training set: Dataset2. k-NN: K-Nearest neighbors; SVM: Support Vector Machine; DT: Decision Tree.

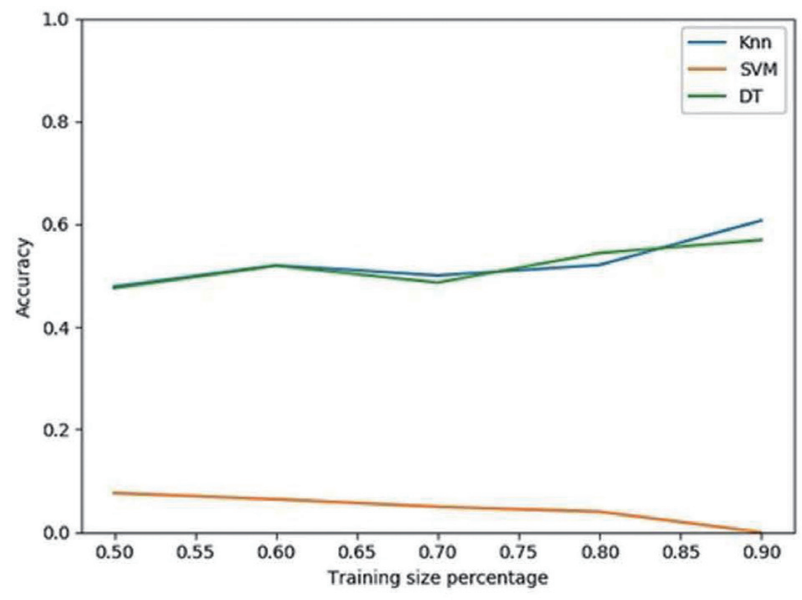

Fig. 7. Accuracy of classification and different sizes of the training set: Dataset3. k-NN: K-Nearest neighbors; SVM: Support Vector Machine; DT: Decision Tree.

Table 6. Confusion matrix regarding the classification of Dataset 3 with nine classes (CI, $\mathrm{CO}, \mathrm{BCI}, \mathrm{BCO}, \mathrm{MCI}, \mathrm{MCO}$, $\mathrm{ACI}, \mathrm{ACO}$ and $\mathrm{CPc}$ ) using $\mathrm{k}-\mathrm{NN}$ and $60 \%$ of the samples for the training set.

\begin{tabular}{|c|c|c|c|c|c|c|c|c|c|}
\hline \multirow{2}{*}{$\begin{array}{l}\text { True class } \\
(\%)\end{array}$} & \multicolumn{9}{|c|}{ Classified as (\%) } \\
\hline & CI & $\mathrm{CO}$ & BCI & $\mathrm{BCO}$ & MCI & $\mathrm{MCO}$ & ACI & $\mathrm{ACO}$ & $\mathrm{CPc}$ \\
\hline $\mathrm{CI}$ & 84 & 16 & 0 & 0 & 0 & 0 & 0 & 0 & 0 \\
\hline $\mathrm{CO}$ & 0 & 100 & 0 & 0 & 0 & 0 & 0 & 0 & 0 \\
\hline $\mathrm{BCI}$ & 0 & 0 & 67 & 0 & 6 & 21 & 3 & 3 & 0 \\
\hline $\mathrm{BCO}$ & 5 & 0 & 22 & 57 & 11 & 0 & 3 & 0 & 3 \\
\hline MCI & 0 & 0 & 38 & 3 & 17 & 10 & 24 & 7 & 0 \\
\hline $\mathrm{MCO}$ & 0 & 0 & 0 & 0 & 17 & 24 & 31 & 28 & 0 \\
\hline ACI & 0 & 0 & 0 & 0 & 3 & 30 & 55 & 12 & 0 \\
\hline $\mathrm{ACO}$ & 0 & 0 & 0 & 0 & 30 & 11 & 44 & 15 & 0 \\
\hline $\mathrm{CPc}$ & 0 & 0 & 0 & 0 & 0 & 0 & 0 & 0 & 100 \\
\hline
\end{tabular}

CI: inhalation control group; CO: oral control group; BCI: inhalation low 2,4-D concentration group; BCO: oral low concentration group; MCI: inhalation medium concentration group; $\mathrm{MCO}$ : oral medium concentration group; ACI: inhalation high concentration group; ACO: oral high concentration group; CPc: positive control of chronic exposure. k-NN: k-Nearest neighbors.

Dataset5.

In the confusion matrix for Dataset5, there was good accuracy for $\mathrm{CI}+\mathrm{CO}(78 \%)$ and excellent accuracy for $\mathrm{BCI}+\mathrm{MCI}+\mathrm{ACI}+\mathrm{BCO}+\mathrm{MCO}+\mathrm{ACO}(98 \%)$ and $\mathrm{CPc}$ $(100 \%)($ Table 8$)$.

\section{DISCUSSION}

In the present study, we observed that acute inhalation exposure to the 2,4-D caused DNA damage at the level of a single cell in the comet assay and that chronic exposure resulted in an increase in the number of micronuclei and DNA damage at the level of a single cell regardless of the route of exposure. Machine learning showed a distinction effect between the control groups and those exposed to 2,4-D. Our study added one more data favoring the genotoxicity of 2,4-D. And this data was obtained under conditions and concentrations of environmental exposure (oral and inhaled) to 2,4-D.

Inhalation exposure is the main route of occupational exposure, while the oral route, through contaminated food or water, is the main route of non-occupational exposure, not only for exposure to the 2,4-D, but also to other pesticides (RED, 2005). Therefore, in this study, we chose to evaluate these two routes of exposure.

The significant increase in the use of pesticides has 
Genotoxicity of 2,4-dichlorophenoxyacetic

Table 7. Confusion matrix regarding the classification of Dataset 4 with five classes $(\mathrm{CI}, \mathrm{CO}, \mathrm{BCI}+\mathrm{MCI}+\mathrm{ACI}$, $\mathrm{BCO}+\mathrm{MCO}+\mathrm{ACO}$ and $\mathrm{CPc}$ ) using $\mathrm{DT}$ and $80 \%$ of the samples for the training set.

\begin{tabular}{lccccc}
\hline True class (\%) & \multicolumn{5}{c}{ Classified as (\%) } \\
\cline { 2 - 6 } & CI & CO & BCI+MCI+ACI & BCO+MCO+ACO & CPc \\
\hline CI & $\mathbf{8 8}$ & 3 & 6 & 3 & 0 \\
BCI+MCI+ACI & 0 & $\mathbf{1 0 0}$ & 0 & $\mathbf{6 4}$ & 36 \\
BCO+MCO+ACO & 0 & 0 & 31 & $\mathbf{6 1}$ & 0 \\
CPc & 4 & 0 & 0 & 15 & 3 \\
\hline
\end{tabular}

CI: inhalation control group; CO: oral control group; BCI: inhalation low 2,4-D concentration group; BCO: oral low concentration group; MCI: inhalation medium concentration group; MCO: oral medium concentration group; ACI: inhalation high concentration group; ACO: oral high concentration group; CPc: positive control of chronic exposure. DT: Decision Tree.

Table 8. Confusion matrix regarding the classification of Dataset5 with three classes $(\mathrm{CI}+\mathrm{CO}$, $\mathrm{BCI}+\mathrm{MCI}+\mathrm{ACI}+\mathrm{BCO}+\mathrm{MCO}+\mathrm{ACO}$ and $\mathrm{CPc}$ ) using $\mathrm{DT}$ and $80 \%$ of the samples for the training set.

\begin{tabular}{lccc}
\hline \multirow{2}{*}{ True class (\%) } & \multicolumn{3}{c}{ Classified as $(\%)$} \\
\cline { 2 - 4 } & $\mathrm{CI}+\mathrm{CO}$ & $\mathrm{BCI}+\mathrm{MCI}+\mathrm{ACI}+\mathrm{BCO}+\mathrm{MCO}+\mathrm{ACO}$ & $\mathrm{CPc}$ \\
\hline $\mathrm{CI}+\mathrm{CO}$ & $\mathbf{7 8}$ & 22 & 0 \\
$\mathrm{BCI}+\mathrm{MCI}+\mathrm{ACI}+\mathrm{BCO}+\mathrm{MCO}+\mathrm{ACO}$ & 2 & $\mathbf{9 8}$ & 0 \\
$\mathrm{CPc}$ & 0 & 0 & $\mathbf{1 0 0}$ \\
\hline
\end{tabular}

CI: inhalation control group; CO: oral control group; BCI: inhalation low 2,4-D concentration group; BCO: oral low concentration group; $\mathrm{MCI}$ : inhalation medium concentration group; $\mathrm{MCO}$ : oral medium concentration group; ACI: inhalation high concentration group; ACO: oral high concentration group; CPc: positive control of chronic exposure. DT: Decision Tree.

caused numerous harmful effects on the health of individuals and animals (Siqueira et al., 2012). The micronucleus test and comet assay are techniques used to assess the genotoxic and mutagenic changes that may precede the development of cancer (Hovhannisyan, 2010).

In acute exposure, the different concentrations of 2,4-D tested did not increase the micronucleus count in the mice compared to the control group. In a previous study that treated male and female mice with $2,4-\mathrm{D}$ by gavage at different concentrations (300, 675, 1050 and $1800 \mathrm{mg} / \mathrm{kg}$ ) in a single time interval, there was also no increase in micronuclei in the bone marrow cells (Charles et al., 1999).

Although we did not observe an increase in the number of micronuclei in acute exposure, exposure to medium and high concentrations of 2,4-D induced DNA damage in the comet assay (score 4) regardless of the number of nebulizations. The same results were observed in a previous study using Chinese hamster ovary cells and the comet assay. In this previous study, ovary cells were treated with 2.6 and $10 \mu \mathrm{L} / \mathrm{mL}$ 2,4-D in a single dose, resulting in a dose-dependent increase in the frequency of DNA strand breaks due to the herbicide (González et al., 2005). In another study using mice treated at doses of $1.7,3.3$ and $33 \mathrm{mg} / \mathrm{kg}$ of body weight by gavage for 3 and $5 \mathrm{con}-$ secutive days, 2,4-D showed a genotoxic effect (Amer and Aly, 2001). However, these studies were performed using high doses of 2,4-D and by routes that do not reflect human exposure.

More than one genotoxicity or mutagenicity test must be performed to assess the presence of DNA damage as well as to assess the DNA damage type (Hovhannisyan, 2010). The micronucleus test and the comet assay assess different damage. The micronucleus test measures chromosomal loss and/or breakage of a chromosome. Therefore, the micronucleus test evaluates clastogenic substances (which cause chromosome breakage) or aneugenic substances (which lead to whole chromosomes not completing anaphasic migration of cell division). The comet assay detects breaks in a DNA strand and alkali-labile sites, breaks in both strands of DNA as well as breaks in sites where there has been incomplete repair involving excision of the bases. In the comet assay, the amount of DNA in the tail is proportional to the number of strand breaks. Thus, larger comet tails indicate greater breaks (Hovhannisyan, 2010). This difference between the tests justifies the observation of no increase in the number of micronuclei but an increase in damage in the comet assay with acute exposure to 2,4-D. The observation of micronuclei induction suggests that at least some of the damage induced by environmental exposure to medium and high 
concentration 2,4-D is not repaired.

There are few studies in the literature that have performed chronic experimental exposure to pesticides. With chronic exposure, we observed a significant increase in micronuclei in all exposed groups regardless of the route of exposure. In addition, we observed a significant increase in the score of 4 (greater damage) in the comet assay in all exposed groups, except in the group exposed to low oral concentration of 2,4-D, regardless of the route of exposure. Previous studies with long-term human exposure to pesticides have shown an increase in the tail length of comets in the exposed groups (Ali et $a l ., 2018)$ and an increase in the number of micronuclei in exfoliated oral epithelial cells (Tomiazzi et al., 2018). Although it was not statistically significant, we observed a slight increase in micronucleus number in acute exposure of animals exposed to high concentration in the $72 \mathrm{hr}$ interval but with damage recovery after $192 \mathrm{hr}$ of exposure. These data agreed with the findings of the chronic phase, indicating a higher probability of longer exposure time resulting in the formation of micronuclei. Our work corroborates the genotoxic potential of pesticides, specifically $2,4-\mathrm{D}$, mainly in chronic exposure.

The carcinogenicity of 2,4-D may be associated with a concentration of dioxins. Some studies have shown a small increase in the risk of cancer in workers exposed to herbicides contaminated with higher chlorinated dioxins (Kogevinas et al., 1997). However, other studies show that there is no increased risk for all types of cancer at lower levels of exposure to dioxins (McBride et al., 2018). In our study, the 2,4-D formulation is in accordance with the concentration of dioxins assessed as permissible by IARC (IARC, 2015). Thus, the genotoxic effects that we observed do not appear to be associated with dioxins.

Although we observed greater DNA damage both to the micronucleus test and the comet assay in both phases of exposure (acute and chronic) at higher doses of 2,4-D, this increase in damage was not statistically significant. This data shows the possibility that 2,4-D has a dose at which it has maximum genotoxic effects. And from this dose, the increase in damage is small to the point of not being significantly different upon exposure to higher doses. Studies that evaluate the internal dose of 2,4-D for each animal exposed to the concentrations of environmental exposure may provide a better understanding of the possible dose-response effects.

Recognition pattern is one of the most prominent functions in Artificial Intelligence (Papa et al., 2012). Different studies have shown the effectiveness of using machine learning in the biological and medical fields (Yılmaz et al., 2016; Tomiazzi et al., 2018; Vieira et al., 2019). The evaluation of data made through machine learning, makes the analysis non-subjective, which can happen in relation to statistical analysis.

In the acute phase, the machine learning analysis identified a pattern in the distribution of genotoxic effects in groups exposed to the herbicide at different concentrations (Dataset2) with the classification performance of groups exposed to 2,4-D (BC+MC+AC) being $81 \%$. This finding indicated that there is a clear difference between groups exposed and not exposed to 2,4-D. This difference is probably associated with the results of the comet assay, in which DNA damage was observed in groups exposed to 2,4-D.

In the same dataset, the accuracy of the control group (C) was equal to $47 \%$, but $53 \%$ were confused with groups exposed to 2,4-D (BC+MC+AC). This confusion between the control group exposed to saline solution (C) and the groups exposed to 2,4-D may be associated with the fact that we did not find any difference in the micronucleus count between these two groups.

In the chronic phase with the first analysis (Dataset3), the control groups showed excellent accuracy ranging from 84 to $100 \%$, but the groups exposed to 2,4-D showed confusion. When we grouped based on inhalation exposure to 2,4-D (BCI+MCI+ACI) and oral exposure to 2,4-D (BCO+MCO+ACO), the accuracy of these groups was good (64 and $61 \%$, respectively), showing no difference between concentrations. However, these groups were still confused. When unifying all groups exposed to 2,4-D (BCI+MCI+ACI+BCO+MCO+ACO) (Dataset5), the accuracy was excellent (98\%). The algorithm recognized them more robustly (98\%), showing that chronic exposure to 2,4-D can cause a genotoxic effect regardless of the route of exposure and concentration.

The machine learning analysis reinforced the results found in the statistical analysis of both the acute and chronic phases of the experiment. In addition, machine learning analysis showed to be an effective tool in identifying patterns in the results of genotoxic characteristics.

The present study concluded that 2,4-D causes both clastogenic or aneugenic damage as well as DNA strand breakage through acute and chronic exposure to environmental concentrations relevant to human exposure. Machine learning showed that the effects of exposure are neither concentration-dependent nor route-dependent but that there is a clear distinction between the control groups and those exposed to 2,4-D. Thus, greater care is needed in the application of 2,4-D in crops because its use can cause health risk. 
Genotoxicity of 2,4-dichlorophenoxyacetic

\section{ACKNOWLEDGMENTS}

This work was funded by research funds from the Universidade do Oeste Paulista (UNOESTE) and carried out with support from the Coordination for the Improvement of Higher Education Personnel - Brazil (CAPES) Financing Code 001. F. M. Azevedo was a CAPES fellow. P. H. N. Chagas was a fellow in the Scientific Initiation Scholarship Program of the National Council for Scientific and Technological Development (PIBIC / CNPq). The authors would like to thank the technician from the Genetics Laboratory of the Universidade do Oeste Paulista (UNOESTE), Mayara de Oliveira Vidotto Figueiredo, for the help in carrying out the Comet Assay.

Conflict of interest---- The authors declare that there is no conflict of interest.

\section{REFERENCES}

Ali, T., Ismail, M., Asad, F., Ashraf, A., Waheed, U. and Khan, Q.M. (2018): Pesticide genotoxicity in cotton picking women in Pakistan evaluated using comet assay. Drug Chem. Toxicol., 41, 213220.

Amer, S.M. and Aly, F.A. (2001): Genotoxic effect of 2,4-dichlorophenoxy acetic acid and its metabolite 2,4-dichlorophenol in mouse. Mutat. Res., 494, 1-12.

Burrel, J. (2016): How the machine 'thinks': understanding opacity in machine learning algorithms. Big Data Soc., 3, 1-12.

Bus, J.S. and Hammond, E.L. (2007): Regulatory progress, toxicology, and public concerns with 2,4-D: where do we stand after two decades? Crop Prot., 26, 266-269.

Carvalho, D.R. and Dallagassa, M.R. (2014): Mineração de dados: aplicações, ferramentas, tipos de aprendizado e outros subtemas. AtoZ., 3, 82-86.

Charles, J.M., Cunny, H.C., Wilson, R.D., Ivett, J.L., Murli, H., Bus, J.S. and Gollapudi, B. (1999): In vivo micronucleus assays on 2,4-dichlorophenoxyacetic acid and its derivatives. Mutat. Res., 444, 227-234.

El Kabbaoui, M., Chda, A., El-Akhal, J., Azdad, O., Mejrhit, N., Aarab, L., Bencheikh, R. and Tazi, A. (2017): Acute and subchronic toxicity studies of the aqueous extract from leaves of Cistus ladaniferus L. in mice and rats. J. Ethnopharmacol., 209, 147-156.

Gollapudi, B.B., Charles, J.M., Linscombe, V.A., Day, S.J. and Bus, J.S. (1999): Evaluation of the genotoxicity of 2,4-dichlorophenoxyacetic acid and its derivatives in mammalian cell cultures. Mutat. Res., 444, 217-225.

González, M., Soloneski, S., Reigosa, M.A. and Larramendy, M.L. (2005): Genotoxicity of the herbicide 2,4-dichlorophenoxyacetic and a commercial formulation, 2,4-dichlorophenoxyacetic acid dimethylamine salt. I. Evaluation of DNA damage and cytogenetic endpoints in Chinese Hamster ovary (CHO) cells. Toxicol. In Vitro, 19, 289-297.

Hoar, S.K., Blair, A., Holmes, F.F., Boysen, C.D., Robel, R.J., Hoover, R. and Fraumeni, J.F. Jr. (1986): Agricultural herbicide use and risk of lymphoma and soft-tissue sarcoma. JAMA, 256,
1141-1147.

Hovhannisyan, G.G. (2010): Fluorescence in situ hybridization in combination with the comet assay and micronucleus test in genetic toxicology. Mol. Cytogenet., 3, 17.

International Agency for Research on Cancer (IARC). (2015): DDT, Lindane, and 2,4-D. IARC Monographs on the Evaluation of Carcinogenic Risks to Humans. Volume 113. IARC. Lyon. http://monographs.iarc.fr/ENG/Monographs/vol113/index.php (accessed 14 January 2019).

Kogevinas, M., Becher, H., Benn, T., Bertazzi, P.A., Boffetta, P., Bueno-de-Mesquita, H.B., Coggon, D., Colin, D., Flesch-Janys, D., Fingerhut, M., Green, L., Kauppinen, T., Littorin, M., Lynge, E., Mathews, J.D., Neuberger, M., Pearce, N. and Saracci, R. (1997): Cancer mortality in workers exposed to phenoxy herbicides, chlorophenols, and dioxins. An expanded and updated international cohort study. Am. J. Epidemiol., 145, 1061-1075.

MacGregor, J.T., Heddle, J.A., Hite, M., Margolin, B.H., Ramel, C., Salamone, M.F., Tice, R.R. and Wild, D. (1987): Guidelines for the conduct of micronucleus assays in mammalian bone marrow erythrocytes. Mutat. Res., 189, 103-112.

McBride, D.I., Collins, J.J., Bender, T.J., Bodner, K.M. and Aylward, L.L. (2018): Cohort study of workers at a New Zealand agrochemical plant to assess the effect of dioxin exposure on mortality. BMJ Open, 8, e019243.

Mello, F.A., Quinallia, G., Marion, A.L., Jorge, F.C., Marinelli, L.M., Salge, A.K.M., Fagiani, M.A.B., Mareco, E.A., Favareto, A.P.A. and Silva, R.C.R. (2018): Evaluation of the nasal cavity mice submitted to the inhalation exposure to the herbicide 2,4dichlorophenoxyacetic acid, Medicina (Ribeirão Preto, Online), 51, 247-253.

National Research Council. (2011): Guide for the care and use of laboratory animals, eighth edition, The National Academies Press, Washington, DC. doi: https://doi.org/10.17226/12910

Paiva, F.P., Mafilli, V.V. and Santos, A.C. (2005): Curso de Manipulação de Animais de Laboratório. Fundação Osvaldo Cruz, Centro de Pesquisas Gonçalo Muniz. http://www.bioteriocentral. ufc.br/arquivos/apostilha_manipulacao.pdf, 2005 (accessed 22 August 2015).

Papa, J.P., Falcão, A.X., Albuquerque, V.H. and Tavares, J.M. (2012): Efficient supervised optimum-path forest classification for large datasets. Pattern Recognit., 45, 512-520.

Pereira, D.R., Papa, J.P., Saraiva, G.F. and Souza, G.M. (2018): Automatic classification of plant electrophysiological responses to environmental stimuli using machine learning and interval arithmetic. Comput. Electron. Agric., 145, 35-42.

Reregistration Eligibility Decision (RED). (2005): 2,4-D EPA 738R-05-002. U.S. Environmental Protection Agency, Office of Prevention, Pesticides and Toxic Substances, Office of Pesticide Programs, U.S. Government Printing Office: Washington, DC.

Ruiz de Arcaute, C., Larramendy, M.L. and Soloneski, S. (2018): Genotoxicity by long-term exposure to the auxinic herbicides 2,4-dichlorophenoxyacetic acid and dicamba on Cnesterodon decemmaculatus (Pisces: poeciliidae). Environ. Pollut., 243 (Pt A), 670-678.

Sbano, A., Ferreira, J.V., Peckle, B.A., Macrae, A. and Direito, I.C. (2013): Otimização de método cromatográfico para quantificação do herbicida ácido 2,4-Diclorofenoxiacético (2,4-D). Acta Sci. Technol., 1, 37-46.

Scherer, K. and Strohschoen, A.A. (2013): Padronização do teste cometa para análise de genotoxicidade como atividade de ensino para graduação na área da saúde. Revista Destaques Acadêmicos., $\mathbf{5}, 49-60$. 


\section{F. de Azevedo Mello et al.}

Singh, N.P., McCoy, M.T., Tice, R.R. and Schneider, E.L. (1988): A simple technique for quantitation of low levels of DNA damage in individual cells. Exp. Cell Res., 175, 184-191.

Siqueira, D.F., Moura, R.M., Laurentino, G.E., Araújo, A.J. and Cruz, S.L. (2012): Análise da exposição de trabalhadores rurais a agrotóxicos. Ver Bras Promoc Saúde, 26, 182-191.

Song, Y. (2014): Insight into the mode of action of 2,4-dichlorophenoxyacetic acid $(2,4-D)$ as an herbicide. J. Integr. Plant Biol., 56, 106-113.

Tolbert, P.E., Shy, C.M. and Allen, J.W. (1992): Micronuclei and other nuclear anomalies in buccal smears: methods development. Mutat. Res., 271, 69-77.

Tomiazzi, J.S., Judai, M.A., Nai, G.A., Pereira, D.R., Antunes, P.A. and Favareto, A.P. (2018): Evaluation of genotoxic effects in Brazilian agricultural workers exposed to pesticides and cigarette smoke using machine-learning algorithms. Environ. Sci.
Pollut. Res. Int., 25, 1259-1269.

Vapnik, V.N. (1999): An overview of statistical learning theory. IEEE Trans. Neural Netw., 10, 988-999.

Vieira, K.C., Fernandes, A.Á., Silva, K.M., Pereira, V.R., Pereira, D.R. and Favareto, A.P. (2019): Experimental exposure to gasohol impairs sperm quality with recognition of the classification pattern of exposure groups by machine learning algorithms. Environ. Sci. Pollut. Res. Int., 26, 3921-3931.

Villela, I.V., de Oliveira, I.M., da Silva, J. and Henriques, J.A. (2006): DNA damage and repair in haemolymph cells of golden mussel (Limnoperna fortunei) exposed to environmental contaminants. Mutat. Res., 605, 78-86.

Yılmaz, A., Arı, S. and Kocabıçak, Ü. (2016): Risk analysis of lung cancer and effects of stress level on cancer risk through neurofuzzy model. Comput. Methods Programs Biomed., 137, 35-46. 